\title{
How green composite materials could benefit aircraft construction
}

\author{
SOUTIS Constantinos $^{1 *}$, YI XiaoSu ${ }^{2} \&$ BACHMANN Jens ${ }^{3}$ \\ ${ }^{1}$ Aerospace Research Institute, University of Manchester, Manchester M13 9PL, UK; \\ ${ }^{2}$ Faculty of Science and Engineering, University of Nottingham Ningbo China, Ningbo 315100, China; \\ ${ }^{3}$ DLR German Aerospace Center, Institute of Composite Structures and Adaptive Systems, Lilienthalplatz 7, Braunschweig 38108, Germany
}

Received December 19, 2018; accepted March 7, 2019; published online June 13, 2019 $\begin{array}{ll}\text { Citation: } & \text { Soutis C, Yi X S, Bachmann J. How green composite materials could benefit aircraft construction. Sci China Tech Sci, 2019, 62: 1478-1480, https:// } \\ \text { doi.org/10.1007/s11431-018-9489-1 }\end{array}$

Aeronautical composite materials can be typically characterized by their excellent mechanical properties, light weight and high performance when compared to the more conventional materials, and the ability to tailor their structure to produce more aerodynamically efficient structural configurations. Considering though the environmental challenge and related public concerns, the game is nowadays changing focusing on renewables [1,2]. Historically, it might not be surprising, if one knows that the earliest aircraft structures, like the first flight of the Wright Brothers' Flyer 1, in North Carolina on December 17th 1903, were made from natural materials such as wood, wire and fabric. Wooden structures did persist until World War II and the de Havilland mosquito aircraft (DH98) constructed of a plywood-balsa-plywood sandwich laminate probably represents the high point of engineering design with wood. The DH91 Albatross airliner in 1937 was moulded as a ply-balsa-ply sandwich construction and the Spitfire fuselage in 1940 was designed and built of Gordon Aerolite material that was a phenolic resin incorporating untwisted flax fibres that could be regarded as the precursor of modern fibre reinforced plastics [3]. European and Chinese scientists and engineers are currently working in association in the ECO-COMPASS project (www.eco-compass.eu) to develop low cost aeronautical green composites. This news article aims to give an overview of the topics and report main results obtained in the ECOCOMPASS project that could be of interest to the journal's readership. The composites under investigation are made

*Corresponding author (email: constantinos.soutis@manchester.ac.uk) from naturally renewable resources like plants and recycled carbon fibres with added functionality, where acoustic, vibration and electrical behaviour can be tuned according to design needs [2]. It is the objective of the joint effort to trialmanufacture secondary and interior structures for aircraft by using these newly developed material systems. The threshold for the introduction of new materials in aviation is comparatively high because of the challenging safety requirements. An example is the fire performance criteria for materials used in the cabin environment.

Biopolymers derived from natural resources are attracting the attention to replace traditional petrol-based plastics in designing eco-friendly commodity bio-composites [4]. For green aviation however, it is the priority to develop biosourced high-performance resins to substitute the traditional epoxies for use in structural applications. Rosin acid [5] and itaconic acid [6] have thus been synthesized, and formulated epoxy resins have been subsequently manufactured to produce green composites [7] through genetic engineering technology. Equivalent and in some cases improved performance have been found in these matrix systems. Furthermore, an intrinsically flame-retardant epoxy resin (diglycidyl ether of daidzein (DGED)) from renewable daidzein has been synthesized without addition of any flame-retardant element $[8,9]$. The latest activities related to the bio-resins have focused on the introduction of nanofillers into the biobased epoxy matrix and the preparation of specimens for mechanical and fire retardant testing. Silicon carbide nanoparticles, carbon nanotubes and nanoclays have been selected as nanofillers to improve thermal, mechanical and 
conductive performance of the cured thermosets. To disperse the nanofillers, high speed mixing followed by sonication has been used as method to disperse the nanofillers into the epoxy matrix. This method has been optimized after several trials and some nano particles have been previously functionalized and the mixtures formulated to improve the dispersion and the quality of the cured samples. After thermal and dispersion characterization, neat resin and nano-modified resin tensile, compression and fire retardancy specimens have been developed. Tensile and compressive tests have been performed to the neat resins showing values comparable to the currently used epoxies in this field. As next steps, mechanical and fire retardancy characterization of the nanofilled resins will be performed to compare the results to the ones of neat specimens.

The poor interfacial property between the hydrophilic plant fibres and the hydrophobic polymeric matrices results obviously in low mechanical properties; this becomes one of the major obstacles for their structural application, if thinking of partially replacing the traditional glass fibre as reinforcement. A multi-scale shear lag model was proposed in the ECO-COMPASS project to take the full advantages of the hierarchical structure of the plant fibre reinforced composites $[10,11]$. It is demonstrated that not only the fracture toughness, interfacial shear strength, tensile strength and modulus are improved by the component hybridization, nanoparticle grafting and nano-modification [12], but also the fire retardation and the anti-microbial performances $[13,14]$. Moreover, the unique hollow structure of the plant fibres can provide additional benefit in structural damping, noise reduction and heat isolation compared to glass or carbon fibre counterparts, behaviour that is exactly desired for an aircraft interior structure $[15,16]$. Additionally to the improvement of pure plant fibre reinforced polymer properties, the utilization of valuable recycled carbon fibres $(\mathrm{rCF})$ as an alternative way to enhance properties of eco-resins has been considered. The downcycled rCF usually retain their excellent mechanical properties but are discontinuous and cannot simply replace long virgin carbon fibres (vCF). Therefore, wet-laid [12] and carded [17] hybrid nonwoven of flax and $\mathrm{rCF}$ were produced. Positive effects on the flexural properties can be observed by adding even small amounts of rCF. Topically Boeing have recently announced a collaboration with ELG Carbon Fibre to recycle scrap carbon composites left over from the construction of B777X and B787 Dreamliner to be recycled into cars and consumer goods. These fibres need to be converted to continuous forms with improved fibre alignment and designed interface in order to maximise their value in the final product.

One viable strategy for enhancing the innovation level of green composites while addressing mass and volume constraints for the more composite aircraft is the notion of material multifunctionality, typically the electrical conductivity for structural composites in order to detect cracking [18], shield the electromagnetic interference and to protect from a lightning strike. For example, the lightning electrical energy will transform to thermal energy at the insulated resin-rich regions in the composite laminates and vaporize the resins adjacent to the surface instantly. There will be then the secondary mechanical impact, cracks will be formed, and eventually developed into delamination which occurs also at the resin-rich interlaminar (between plies) regions. Accordingly, a functionalized interlayer technology (FIT) was proposed which can simultaneously increase the electrical conductivity and the interlaminar fracture toughness [19]. Following this concept, a coupled electrical-thermal-pyrolytic model was constructed. It shows that the lightning strike damage is strongly governed by the anisotropic electrical properties of the carbon fibre composite, and the lightning current waveform has certain effect on the damage extent [20]. Thus, a lightning damage criterion was proposed to evaluate the in-plane damage by temperature dependent model and to estimate the in-depth damage by pyrolysis dependent model [21]. Further investigation is going to quantitatively understand the mechanism of the lightning strike on the composite laminates, supported by the experimental lightning strike test. The effort on life cycle assessment [22] of these green composites will be continued.

In summary, the emergence of bio-sourced and multifunctional green composites offers a unique opportunity to combine the resource and environment with materials and aircraft in new ways that can not only provide an alternative way for aeronautical structures, but also expand state-of-theart technologies. A case study from the ECO-COMPASS project can, for example, be demonstrated wherein the biosourced epoxy composite using SoA carbon fibres is being engineered to manufacture empennage side panel with lightning strike protection (Figure 1). Although preliminary, the present research has highlighted materials-enabled po-

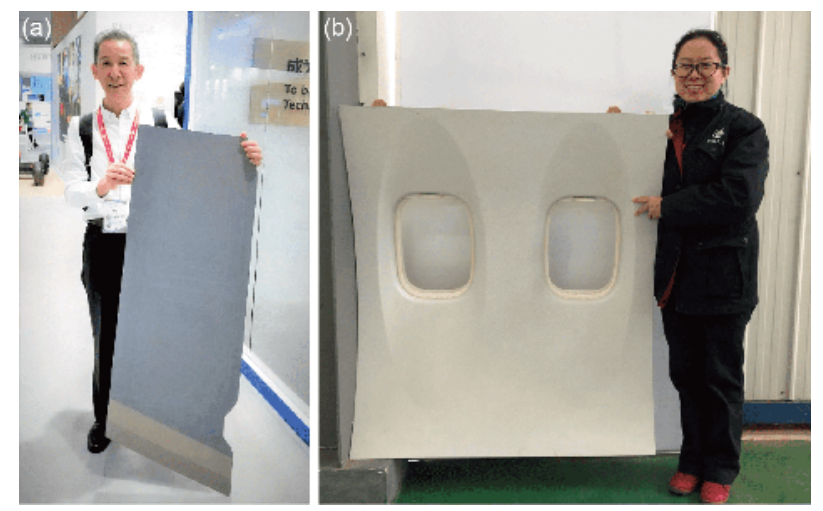

Figure 1 (Color online) (a) Demonstration of an empennage side panel made of bio-sourced epoxy composites with lightning strike protection for C919, courtesy of Weiping Liu, COMAC; (b) interior panel made of ramie fibre fabric, bio-based epoxy and green honeycomb for MA 600, courtesy of Fangbo Ding, XAC-AVIC. 
tential, and an alternative solution to the CLEAN SKY target. Work is now continuing to optimize the properties of these material systems and understand the fundamental issues that affect their performance; analytical and experimental data have appeared in international journals and conferences. Of course, it should be emphasized that affordability is the key to survival in aerospace and other industries, and therefore effort is devoted to low cost manufacturing methods in addition to analysis and computational simulation of the manufacturing and assembly process. The simulation of the structural performance [23], is intimately connected and further progress will be reported in near future publications.

1 Bachmann J, Hidalgo C, Bricout S. Environmental analysis of innovative sustainable composites with potential use in aviation sectorA life cycle assessment review. Sci China Tech Sci, 2017, 60: 13011317

2 Bachmann J, Yi X, Gong H, et al. Outlook on ecologically improved composites for aviation interior and secondary structures. CEAS Aeronaut J, 2018, 9: 533-543

3 Soutis C. Introduction: Engineering Requirements for Aerospace Composite Materials. In: Irving P E, Soutis C, eds. Polymer Composites in the Aerospace Industry. Elsevier, Woodhead Publishing, 2015. 1-17

4 Ramon E, Sguazzo C, Moreira P. A review of recent research on biobased epoxy systems for engineering applications and potentialities in the aviation sector. Aerospace, 2018, 5: 110

5 Li C, Liu X, Zhu J, et al. Synthesis, characterization of a rosin-based epoxy monomer and its comparison with a petroleum-based counterpart. J MacroMol Sci Part A, 2013, 50: 321-329

6 Ma S, Liu X, Jiang Y, et al. Bio-based epoxy resin from itaconic acid and its thermosets cured with anhydride and comonomers. Green Chem, 2013, 15: 245-254

7 Dai J, Peng Y, Teng N, et al. High-performing and fire-resistant biobased epoxy resin from renewable sources. ACS Sustain Chem Eng, 2018, 6: 7589-7599

8 Zhang $\mathrm{X} \mathrm{F}, \mathrm{Wu} \mathrm{Y}$, Wei $\mathrm{J} \mathrm{H}$, et al. Curing kinetics and mechanical properties of bio-based composite using rosin-sourced anhydrides as curing agent for hot-melt prepreg. Sci China Tech Sci, 2017, 60:
1318-1331

9 Yi X S, Zhang X, Ding F, et al. Development of bio-sourced epoxies for bio-composites. Aerospace, 2018, 5: 65

10 Li Q, Li Y, Zhou L. A micromechanical model of interfacial debonding and elementary fiber pull-out for sisal fiber-reinforced composites. Compos Sci Tech, 2017, 153: 84-94

11 Wang C, Ren Z, Li S, et al. Effect of ramie fabric chemical treatments on the physical properties of thermoset polylactic acid (PLA) composites. Aerospace, 2018, 5: 93

12 Tse B, Yu X, Gong H, et al. Flexural properties of wet-laid hybrid nonwoven recycled carbon and flax fibre composites in poly-lactic acid matrix. Aerospace, 2018, 5: 120

13 Wang $\mathrm{H}$, Xian $\mathrm{G}$, $\mathrm{Li} \mathrm{H}$. Grafting of nano- $\mathrm{TiO}_{2}$ onto flax fibers and the enhancement of the mechanical properties of the flax fiber and flax fiber/epoxy composite. Compos Part A-Appl Sci Manufacturing, 2015, 76: 172-180

14 Li Y, Yi X, Yu T, et al. An overview of structural-functional-integrated composites based on the hierarchical microstructures of plant fibers. Adv Compos Hybrid Mater, 2018, 1: 231-246

15 Yang W D, Li Y. Sound absorption performance of natural fibers and their composites. Sci China Tech Sci, 2012, 55: 2278-2283

16 Zhang J, Shen Y, Jiang B, et al. Sound absorption characterization of natural materials and sandwich structure composites. Aerospace, 2018, 5: 75

17 Bachmann J, Wiedemann M, Wierach P. Flexural mechanical properties of hybrid epoxy composites reinforced with nonwoven made of flax fibres and recycled carbon fibres. Aerospace, 2018, 5: 107

18 Tserpes K, Kora C. A multi-scale modeling approach for simulating crack sensing in polymer fibrous composites using electrically conductive carbon nanotube networks. Part II: Meso- and macro-scale analyses. Aerospace, 2018, 5: 106

19 Ye L. Functionalized interleaf technology in carbon-fibre-reinforced composites for aircraft applications. Natl Sci Rev, 2014, 1: 7-8

20 Dong Q, Guo Y, Chen J, et al. Influencing factor analysis based on electrical-thermal-pyrolytic simulation of carbon fiber composites lightning damage. Composite Struct, 2016, 140: 1-10

21 Guo Y, Dong Q, Chen J, et al. Comparison between temperature and pyrolysis dependent models to evaluate the lightning strike damage of carbon fiber composite laminates. Compos Part A-Appl Sci Manufacturing, 2017, 97: 10-18

22 Dong S, Xian G, Yi X S. Life cycle assessment of ramie fiber used for FRPs. Aerospace, 2018, 5: 81

23 Soutis C, Beaumont, P W R. Multi-Scale Modelling of Composite Material Systems: The Art of Predictive Damage Modelling. Elsevier, 2005 